\title{
Benchmarks
}

\section{Quality Control PCR: A Method for Detecting Inhibitors of Taq DNA Polymerase}

BioTechniques 27:920-926 (November 1999)

Theoretically, polymerase chain reaction (PCR) makes it possible to amplify DNA sequence from any biological sample. In practice, however, compounds that inhibit PCR may copurify with the DNA template, making amplification impossible. There are numerous reports of DNA extracts that contain inhibitory activity. The extinction of phage $\lambda$ DNA PCR product, caused by the addition of DNA extracts of human remains, indicates the presence of an inhibitor (4). DNA extracts of certain seaweed species can eliminate the production of signal in mouse $\beta$-globin gene PCR (7). PCR as a medical diagnostic tool may be complicated when chain-terminating drugs used in the treatment of viruses inhibit Taq DNA polymerase, producing a false negative in some patients (15). Some foods contain compounds that inhibit PCR, which can produce a false negative in tests for microbial contamination (12). When the template DNA is from soil, humic acid can inhibit PCR (16).

Inhibition is an especially significant problem when extracting DNA from old and ancient material. Postmortem changes of the DNA may prevent amplification. The presence of heme can inhibit PCR that involves extracts of dried blood stains, a problem in forensic genetics (1). The co-purification of collagen with DNA is responsible for inhibition in samples from human remains (13). In other cases, inhibition can be caused by the cross-linking of proteins to the DNA through carbohydrates (10). Inhibitors may not necessarily respond to the addition of adjuncts such as bovine serum albumin (BSA) or singlestranded binding protein (SSB) as shown in some cases (8). Although DNA extraction procedures for museum and fossil specimens are described in the literature $(2,6)$, these techniques are not universally applicable. The chemical diversity of cells and the variety of postmortem histories make it impossi- ble to predict which procedures will work. From a practical standpoint, it is not feasible to identify the inhibitor in every specimen. Developing a DNAtemplate purification method that eliminates or inactivates inhibitors is often a more immediate goal. In cases where the specimen size is small, as in fossil insects, the amount of template is limited, which makes the monitoring of template quality by gel electrophoresis impossible. PCR has the potential to detect nucleic acids in these specimens. Described here is a method that utilizes a modification of quantitative PCR to evaluate the quality of DNA preparations and facilitates the rapid screening of template purification procedures.

PCR can fail because of the presence of inhibitors or the absence of adequate template DNA. It is practical to distinguish two categories of inhibition: $(i)$ inhibitors of Taq DNA polymerase may co-purify with the DNA and (ii) the modification of the DNA template makes it unrecognizable as a substrate for PCR. The addition of a reporter template and primer combination will have different consequences depending on the type of inhibition (Figure 1). Factors that inhibit Taq DNA polymerase that are diffusible in the reaction are indicated by the disappearance of the reporter template product. However, inhibitors bound to the DNA may prevent efficient denaturation, interfere with primer annealing or prevent Taq DNA polymerase from recognizing the DNA. Since this type of inhibition is not diffusible, the addition of such extracts will have no effect on the reporter template product. Distinguishing between nondiffusible inhibition and nonreversible DNA degradation is difficult. Compounds that degrade cross-links, such as N-phenacylthiazolium bromide (PTB) may eliminate inhibition caused by cross-linkages (10). Before concluding that amplifiable DNA is not present in any sample, it is necessary to confirm that inhibitors of Taq DNA polymerase are not present in the preparation.

Quality control (qc)PCR can detect inhibitors that are present in template preparations. This technique was developed in response to the challenge of amplifying DNA sequences from fossil beetles found in packrat (genus $\mathrm{NeO}$ toma) middens. Standard template pu- rification methods on fossil material often do not produce an extract from which DNA can be amplified. To distinguish between amplification failure due to the degradation of DNA from failure because of the presence of an inhibitor, a qcPCR includes an external template and primer pair. In addition, primers for a mitochondrial region make it possible to assess the level of inhibition and the quality of the template simultaneously. The additional template is a reporter template that indicates the presence of Taq DNA polymerase inhibitors (Figure 1). If inhibitors are present, the product band will be reduced or eliminated when compared to a control lane containing no DNA extract. This is a modification of quantitative PCR, in which a template of known concentration is an internal standard that competes for the experimental template (9).

Preliminary experiments involve arthropod specimens with three postmortem histories. An effective method of tissue storage makes use of fresh beetle specimens stored at $-80^{\circ} \mathrm{C}$ or $-20^{\circ} \mathrm{C}$ immediately postmortem (11). Museum specimens of beetles are typically stored in killing jars that contain ethyl acetate and are dried before pinning. Fossil materials are assorted arthropod fragments from carbon-dated packrat middens (3). DNA from dried and fossil material is degraded, and it is therefore critical to target a region high in copy number, but small in size. The target DNA is a 281-bp mitochondrial region that includes part of the 16S rDNA gene and the nicotinamide-adenine dinucleotide dehydrogenase (NADH) subunit 1 gene (ND1). This region is small but has the potential to contain phylogenetically informative sequences. The primers are N1-J-12585 (5'-GGTCCCTTACGAATT TGAATATATRCCT$\left.3^{\prime}\right)$ and LR-J-12866 (5'-ACATGATCTGAGT TCAAACCGG-3'), which amplify this region from a large number of taxa (14). Since qcPCR includes a reporter template and primer set with primers that target the region of interest, the product of the reporter template and the product from the specimen must be distinguishable by size. Also, the primers must not interact with each other, and both reactions must work under the same conditions. $\beta$-glucuronidase 


\section{Benchmarks}

$(G U S)$ is a prokaryotic gene commonly used as a reporter gene in plant bioengineering (5). We have not detected GUS sequences in the beetle genome (Figure 2 , lane 10). Primers were designed for the GUS gene sequence $\left(\right.$ GenBank $^{\circledR}$ Accession No. S69414), using the primer screening algorithms of MacVector $^{\mathrm{TM}}$ sequence analysis software Version 5.0 (Eastman Kodak, Rochester, NY, USA). The upstream primer (GUS-U) is from bp 404-430 of the $5^{\prime}$ end of the gene (5'-ACGAACTGAAC TGGCAGACTATCC-3') and the downstream primer (GUS-D) is from bp 1230-1208 on the $3^{\prime}$ end (5'-AATACTCCACATCACCACGCTTG-3'). The reporter template is the plasmid, pNMT41, which is a clone of the GUS gene in the vector pUC18.

Figure 2 is an example of qcPCR performed to test the effectiveness of treatments with chitinase and $\beta-\mathrm{N}$ acetylglucosaminidase (NAGase) on different specimens. This particular example uses a phenol-based extraction, although resin-based extraction methods give similar results. Previous experiments indicate that treatment of dried specimens with chitinase reduces inhibition of Taq DNA polymerase. However, the complete breakdown of chitin is a two-step process. Chitinase first breaks down the chitin to chitobiose, which is then broken down to $\mathrm{N}$ acetyl-D-glucosamine by NAGase. To determine whether this second step has any effect on the PCR inhibition, DNA extractions are performed on fresh, dried and fossil specimens, with and without the addition of NAGase.

Museum and fossil material is prepared under a laminar flow hood in a different laboratory from the fresh material. Included in each experiment is a sham extraction to which no tissue is added. The sham functions as a negative control that detects the contamination of any reagent with DNA, which might lead to a false positive. Also, the sham indicates if inhibition is a consequence of a compound used in the preparation.

The specimens used in this example included DNA from fresh carabid beetles of the genera Amara, museum specimens of the carabid Stereocerus hematopus collected in 1981 in Manitoba, Canada, and 4000-year-old unsorted arthropod remains from a packrat midden from Big Bend, TX, USA (3). Samples were pulverized in a mortar and pestle to a fine powder in liquid nitrogen. The powder was dispensed to pre-weighed tubes containing chitinase solution. One beetle was used for each treatment that involved either fresh or dried specimens, but the specimens were ground together to ensure sample uniformity within treatments.

Between 10 and $30 \mathrm{mg}$ of tissue were extracted for the fresh and museum samples, and 180-210 $\mathrm{mg}$ for the 
fossil preparations were extracted per treatment. Chitinase (Catalog No. C1525; Sigma, St. Louis, MO, USA) was prepared by resuspending the powder to a concentration of $10 \mathrm{U} / \mathrm{mL}$ in sterile glycerol and stored at $-20^{\circ} \mathrm{C}$. For each sample, $1 \mathrm{U}$ of chitinase was added in a total of $100 \mu \mathrm{L}$ of chitinase buffer $(200 \mathrm{mM}$ potassium phosphate buffer, $\mathrm{pH} 6.0$ and $2 \mathrm{mM} \mathrm{CaCl}_{2}$ ). Incubations were performed with gentle agitation at $25^{\circ} \mathrm{C}$ for at least $2 \mathrm{~h}$. Samples were boiled for $5 \mathrm{~min}$ and cooled on ice. $\mathrm{N}$-acetylglucosaminidase (Catalog No. A-3189; Sigma) was prepared by centrifuging the suspension at a relative centrifical force (RCF) of $16000 \times g$, discarding the supernatant, then resuspending the precipitate in chitinase buffer at a concentration of $0.1 \mathrm{U} / \mu \mathrm{L}$. For each NAGase treatment, $1 \mathrm{U}$ was added and incubated at $37^{\circ} \mathrm{C}$ for at least $30 \mathrm{~min}$. Proteinase $\mathrm{K}$ was added to a final concentration of $0.8 \mathrm{mg} / \mathrm{mL}$ and sodium dodecyl sulfate (SDS) to a concentration of $0.4 \%$ in $0.5 \mathrm{M}$ EDTA at $\mathrm{pH}$ 8.0. Incubation at $37^{\circ} \mathrm{C}$ proceeded for at least $12 \mathrm{~h}$.

The preparations were phenol-chloroform extracted and ethanol-precipitated. Despite a rinse with 70\% ethanol, a white, insoluble precipitate was often present after resuspension in water. The insoluble white precipitate was pelleted by centrifugation at $16000 \times g$ for $30 \mathrm{~s}$, and the supernatant was moved to a Amicon ${ }^{\circledR}$ Microcon ${ }^{\circledR} 100$ Microconcentrator (Millipore, Bedford, MA, USA). The DNA was washed $3 \times$ with water and concentrated to approximately $100 \mu \mathrm{L}$ following the manufacturer's instructions. For each amplification reaction, 5 $\mu \mathrm{L}$ of the DNA extract was added to tubes containing the PCR reagents.

The reactions included $0.5 \mu \mathrm{M}$ of each primer, 5.0 $\mu \mathrm{L}$ DNA extraction to be tested and $1 \mathrm{ng}$ of pNMT41 reporter template. Opti-Prime ${ }^{\mathrm{TM}}$ buffer 7 (Stratagene, La Jolla, CA, USA) (final concentrations: $10 \mathrm{mM}$ Tris, $\mathrm{pH} 8.8,25$ $\mathrm{mM} \mathrm{KCl}, 3.5 \mathrm{mM} \mathrm{MgCl} 2$ ) was used in all reactions. One unit of Taq DNA polymerase was added to each $25 \mu \mathrm{L}$ reaction. A cocktail containing all components except the extracted template DNA was added to each tube. This ensured the addition of the same amount of reporter template to each reaction. The signal intensities between lanes could then be compared, and inhibitor concentrations monitored.

Each experiment included five controls. The sham extraction served as a negative control and detected contamination of DNA extraction reagents and also indicated if inhibitors were introduced during the procedure. Another negative control, in which water replaced the template, detected contamination of PCR reagents. The GUS template and primers were included in one positive control without the addition of any DNA extract to provide a standard for a non-inhibited reaction. Another positive control contained both sets of primers, the GUS template and a positive control extract, allowing for the amplification of both templates. The final control contained the positive control extract, the mitochondrial primers and the GUS primers, but no GUS template. This control insured that the mitochondrial (mt)DNA product could be detected and that GUS-like sequences were not present in the extract. The cycling protocol was as follows: 1 cycle of $96^{\circ} \mathrm{C}$ for $1 \mathrm{~min}, 50^{\circ} \mathrm{C}$ with a $5 \mathrm{~s}$ per degree ramp, $72^{\circ} \mathrm{C}$ for $1 \mathrm{~min} ; 6$ cycles of $96^{\circ} \mathrm{C}$ for $30 \mathrm{~s}, 55^{\circ} \mathrm{C}$ for $1 \mathrm{~min}, 72^{\circ} \mathrm{C}$ for $1 \mathrm{~min}$; 31 cycles of $96^{\circ} \mathrm{C}$ for $30 \mathrm{~s} ; 60^{\circ} \mathrm{C}$ for 1 min, $72^{\circ} \mathrm{C}$ for $1 \mathrm{~min}$ and 1 cycle at $72^{\circ} \mathrm{C}$ for $10 \mathrm{~min}$. Products were fractionated on a $1.0 \%$ agarose gel with $1 \mathrm{mg} / \mathrm{mL}$ ethidium bromide, visualized with UV light and photographed. The molecular weight standards are the $\mathrm{Kb}$ DNA ladder (Stratagene). To quantitate signal intensity, the photographs were scanned, and these digitized images were analyzed with Biomax ${ }^{\circledR}$ 1D Image Analysis software (Eastman Kodak).

Figure 2 shows the three possible outcomes for each experimental reaction: (i) if both 824 and 281 bp bands are present, the reaction is not completely inhibited, and the target template can be amplified, which is the case with the fresh material (lanes 1 and 2); (ii) the presence of only the 824

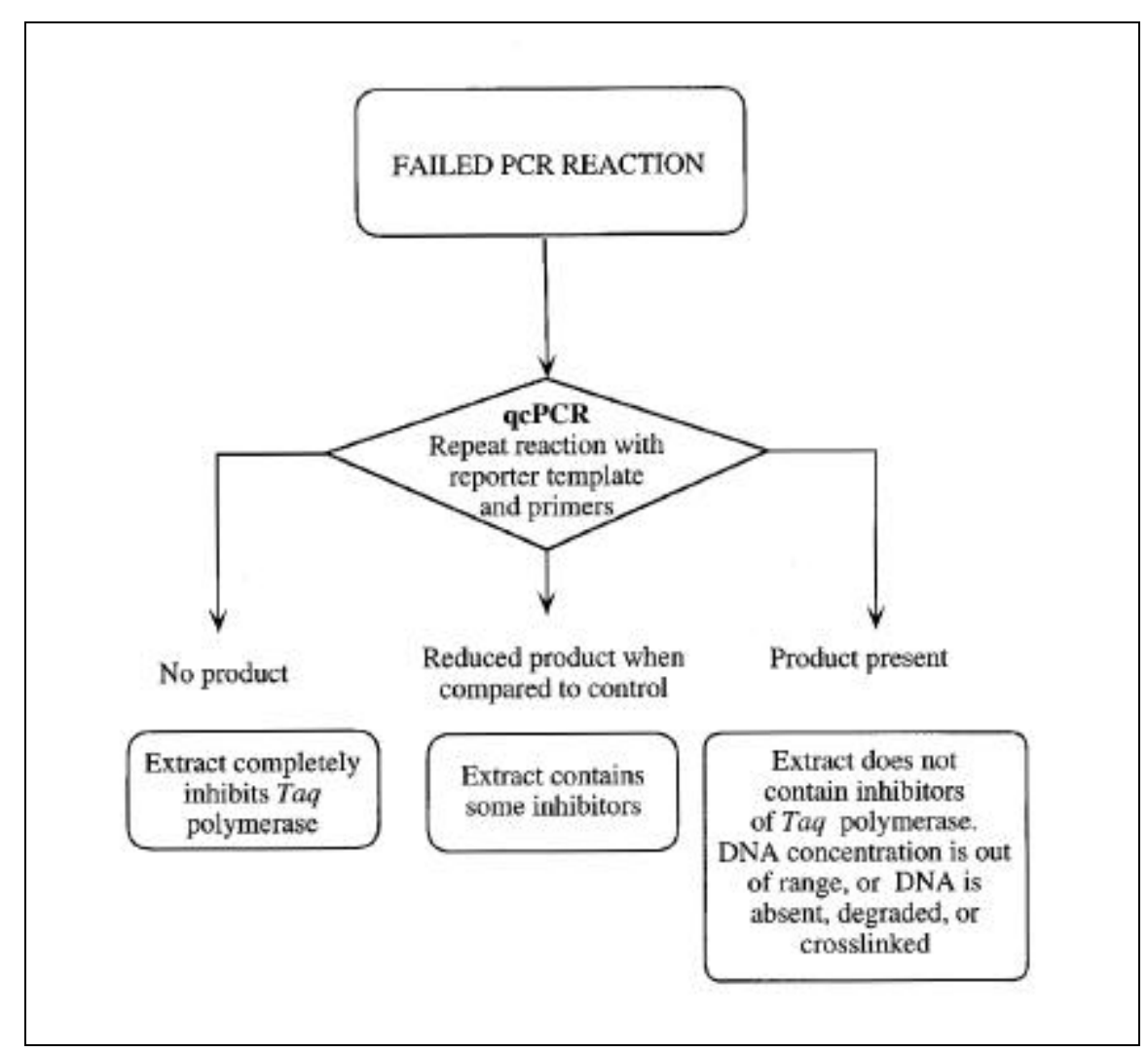

Figure 1. Flowchart for qcPCR. To test PCRs that fail for no apparent reason, the reactions are supplemented with reporter template and primers. If no product is evident when compared with a positive control, the extraction contains inhibitors of Taq DNA polymerase. If a product is present, but exhibits reduced intensity, then some inhibition is present. Adjuncts such as BSA and SSB may relieve this inhibition. If a similar amount of product is visible when compared to the control, the extraction does not contain inhibitors, therefore the DNA concentration or its condition are not adequate for amplification. 
bp reporter GUS band indicates that the inhibitor concentration is reduced sufficiently to permit amplification, but the DNA concentration or the conditions are not optimal for amplification of the target. This is apparent for the museum specimens in lanes 3 and 4. Although the presence of the reporter band justifies the further optimization of template concentration, it may also indicate that no amplifiable DNA is present. The intensity of the GUS band can be used to judge the level of inhibition; and (iii) if no bands are present, then the sample still contains high concentrations of Taq DNA polymerase inhibitors. This is the case in lanes 5 and 6, which contain extracts of fossil material. The sham extraction (lane 7) has the GUS band, so the process itself is not inhibitory, although there is a reduction in intensity from the positive controls (lanes 8, 9 and 11).

Image analysis demonstrates that the intensity of the 824 bp GUS band is reduced by one-third in the samples that contain extract, including the sham control (Figure 2, lanes 1-4 and 7), when compared with the positive controls (Figure 2, lanes 8, 9 and 11). Therefore, this extraction procedure introduces some inhibition that is not inherent in the specimen. The positive controls for each set of primers and template exhibit the appropriate size band (Figure 2, lanes 10 and 11 ) and the negative control has no dis- tinct band (Figure 2, lane 12). The addition of NAGase to the extracts (Figure 2, lanes 2, 4, and 6) has no effect over chitinase alone (Figure 2, lanes 1, 3 and 5).

qcPCR can detect the presence of inhibitors of Taq DNA polymerase. Until the inhibition in the fossil extractions can be eliminated, it is not possible to determine if there is DNA template in these samples. As new procedures become available for the elimination of inhibition, protocols can be easily tested using qcPCR.

Although we developed qcPCR to facilitate the rapid screening of DNA extraction methods for dried specimens and fossil samples, the process has other applications. The mitochondrial primers are based on a comparison of this region for a diverse group of organisms. These primers produce signals in human DNA extracts (unpublished observations). Because GUS is unlikely to be found in eukaryotes, the method is applicable to many other taxa. The problem of falsenegative results in patients treated with chain-terminating drugs would be detected by adding extract from a patient to a qcPCR positive control. The presence of inhibitors in extractions for human forensic analysis would be easily detected with this method. qcPCR is an important control when designing new DNA extraction techniques, extracting DNA from novel sources or using PCR as a diagnostic technique.

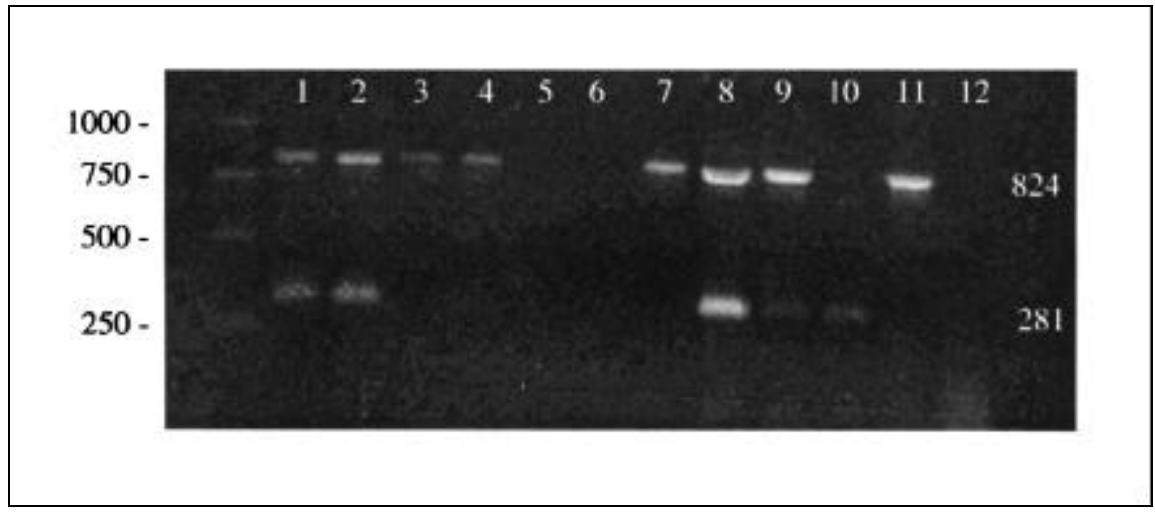

Figure 2. Results. Marker sizes (in bp) are shown on the left, and expected fragment sizes for the GUS band ( $824 \mathrm{bp}$ ) and the mtDNA fragment (281 bp) are indicated on the right. Lane 1, fresh material treated with chitinase; lane 2: Fresh material treated with chitinase and NAGase; lane 3, dried material treated with chitinase; lane 4: Dried material treated with chitinase and NAGase; lane 5, fossil material treated with chitinase; lane 6 , fossil material treated with chitinase and NAGase; lane 7, sham extraction treated with chitinase and NAGase; lane 8, positive control lane with fresh beetle DNA prepared using standard procedures; lane 9, positive control with DNA from a previous extraction experiment; lane 10: Control lane (same as 9), but without GUS template; lane 11, control lane, GUS template and primers with no extract; lane 12, negative control containing both primers, but no template DNA. 


\section{REFERENCES}

1.Alkane, A., K. Matsubara, S. Takahashi and K. Kimura. 1994. Identification of heme compound copurified with deoxyribonucleic acid (DNA) from bloodstains, a major inhibitor of PCR. J. Forensic Sci. 39:362.

2.Cano, R.J. and H.N. Poinar. 1993. Rapid isolation of DNA from fossil and museum specimens. BioTechniques 15:432-436.

3.Elias, S.A. and T.R. Van Devender. 1990 Fossil insect evidence of late Quaternary climatic change in the Big Bend region, Chihuahuan Desert, Texas. Quat. Res. 34:249261.

4.Fox, C.L. 1996. Analysis of ancient mitochondrial DNA from extinct aboringines from Tierra del Fuego-Patagonia. Ancient Biomolecules 1:43-54.

5.Gallagher, S.R. 1992. GUS Protocols: Using The GUS Gene as a Reporter of Gene Expression. Academic Press, San Diego.

6.Goodyear, P.D., S. MacLaughlin-Black and I.J. Mason. 1994. A reliable method for the removal of co-purifying PCR inhibitors from ancient DNA. BioTechniques 16:232-234.

7.Jin, H.J., J.H. Kim, C.H. Sohn, R.E. DeWreede, T.J. Choi, G.H.N. Towers, J.B. Hudson and Y.K. Hong. 1997. Inhibition of Taq DNA polymerase by seaweed extracts from British Columbia, Canada and Korea. J. Appl. Phycology 9:383-388.

8.Kreader, C.A. 1996. Relief of amplification inhibition in PCR with bovine serum albumin or T4 gene 32 protein. Appl. Environ. Microbiol. 62:1102-1106.

9.Larrick, J.W. (Ed.). 1997. The PCR Technique: Quantitative PCR. Eaton Publishing, Natick, MA.

10.Poinar, H.N., M. Hofreiter, W.G. Spaulding, P.S. Martin, B.A. Stankiewicz, H. Bland, R.P. Evershed, G. Possnert and S. Pääbo. 1998. Molecular coproscopy: dung and diet of the extinct ground sloth Nothrotheriops shastensis. Science 281:402-406.

11.Reiss, R.A., D.P. Schwert and A.C. Ashworth. 1995. Field preservation of Coleoptera for molecular genetic analysis. Environ. Entomol. 24:716-719.

12.Rossen, L., P. Nørskov, K. Holmstrøm and O.F. Rasmussen. 1992. Inhibition of PCR by components of food samples, microbial diagnostic assays and DNA-extraction solutions. Int. J. Food Microbiol. 17:37-45.

13.Scholz, M., I. Giddings and C.M. Pusch. 1998. A polymerase chain reaction inhibitor of ancient hard and soft tissue DNA extracts is determinined as human collagen type I. Anal. Biochem. 259:283-286.

14.Simon, C., F. Frati, A. Beckenback, B. Crespi, H. Liu and P. Flook. 1994. Evolution, weighting and phylogenetic utility of mitochondrial gene sequences and a compilation of conserved polymerase chain reaction primers. Ann. Entomol. Soc. Am. 87:651-701.

15.Yedidag, E.N., A.J. Koffron, K.H. Mueller, B. Kaplan, D.B. Kaufman, J.P. Fryer, F.P. Stuart and M. Abecassis. 1996. Acyclovir triphosphate inhibits the diagnostic polymerase chain reaction for cytomegalovirus. Transplantation 62:238-242.
16.Zhou, J., M.A. Bruns and J.M. Tiedje. 1996. DNA recovery from soils of diverse composition. Appl. Environ. Microbiol. 62:316-322.

S. Elias of the University of Colorado and J. Bentancourt of the United States Geological Survey in Tucson provided fossil material. Museum specimens were a gift of D. Schwert and A. Ashworth. The plasmid pNMT41 was a gift of D. Wing. This research was supported in part by a National Science Foundation Small Grant for Exploratory Research EAR-9610416. Address correspondence to Rebecca A. Reiss, Department of Biology, New Mexico Institute of Mining and Technology, Socorro, NM 87801,USA.Internet: reiss@nmt.edu

Received 24 May 1999; accepted 19 July 1999.

\section{Rebecca A. Reiss and Bridget Rutz New Mexico Institute of Mining and Technology Socorro, NM, USA}

\section{Silver-Stained Comet Assay for Detection of Apoptosis}

BioTechniques 27:926-930 (November 1999)

The single-cell gel or comet assay is a sensitive technique for the direct visualization of DNA damage in individual cells (5). In the conventional protocol, cells are sandwiched between thin layers of agarose on a microscope slide, lysed at either alkaline or neutral $\mathrm{pH}$, electrophoresed and stained with a fluorescent dye. During electrophoresis, loops or pieces of DNA migrate away from the nuclear remnant to produce a shape with the visual characteristics of a comet. The distribution of DNA within the cell remnant is then quantitated using tail length or tail moment as expressions of DNA damage $(4,6)$.

The comet assay can also be used to distinguish apoptotic from non-apoptotic cells on the basis of their characteristic signatures or DNA fragmentation patterns (3). Apoptotic cells form structures with large fan-like tails and small heads, as normal or less critically damaged cells form smaller structures with large heads and narrow tails of varying lengths (Figure 1, $a$ and $b$ ). Necrotic cells display relatively large nuclear remnants and thin extended tails, suggestive of random DNA degradation (Figure 1c). Although the detection of apoptosis by the comet assay has been compared to flow cytometry (3), it has not been validated by comparison with the classical cell morphology (CM) assay that is based on chromatin condensation $(1,8)$.

This paper introduces a modified neutral comet (MNC) assay that uses GelBond $^{\circledR}$ film (FMC Bioproducts, Rockland, ME, USA) as a support for agarose and silver stain for the visualization of the comets. The objective of this study was to compare the apoptotic fraction measured by this MNC assay with the CM assay in cell suspensions treated with hydrogen peroxide $\left(\mathrm{H}_{2} \mathrm{O}_{2}\right)$.

Chemicals and solutions. Aqueous solutions (and all dilutions) were made with $18 \mathrm{M} \Omega$ water (Milli-Q Plus PF unit; Millipore, Bedford, MA, USA). A $1 \% \mathrm{wt} / \mathrm{vol}$ agarose solution (high 